RESEARCH METHODOLOGY: INSTRUMENT DEVELOPMENT

\title{
The development and psychometric validation of the self-efficacy and performance in self-management support (SEPSS) Instrument
}

\author{
Veerle Duprez*, Susanne M. Van Hooft*, Jolanda Dwarswaard, AnneLoes van Staa, Ann Van Hecke \\ \& Mathilde M.H. Strating
}

Accepted for publication 27 November 2015

Correspondence to V. Duprez:

e-mail: veerle.duprez@ugent.be

*Both authors contributed equally to this work.

Veerle Duprez MSc RN

PhD Candidate

University Centre for Nursing and Midwifery, Department of Public Health, Faculty of Medicine and Health Sciences, Ghent University, Ghent, Belgium @ucvvgent.be

Susanne M. Van Hooft MSc RN PhD Candidate

Research Centre Innovations in Care, Rotterdam University of Applied Sciences, the Netherlands and Institute of Health Policy \& Management, Erasmus University Rotterdam, Rotterdam, the Netherlands @hsrotterdam

Jolanda Dwarswaard PhD

Senior Researcher

Research Centre Innovations in Care, Rotterdam University of Applied Sciences, the Netherlands and Institute of Health Policy \& Management, Erasmus University Rotterdam, Rotterdam, the Netherlands

AnneLoes van Staa MD PhD RN Professor Transitions in Care Research Centre Innovations in Care, Rotterdam University of Applied Sciences, the Netherlands and Institute of Health Policy \& Management, Erasmus University Rotterdam, Rotterdam, the Netherlands continued on page 1382
DUPREZ V., VAN HOOFT S.M., DWARSWAARD J., VAN STAA A.L., VAN HECKE A. \& STRATING M.M.H. (2016) The development and psychometric validation of the self-efficacy and performance in self-management support (SEPSS) Instrument. Journal of Advanced Nursing 72(6), 1381-1395. doi: 10.1111/ jan.12918

\begin{abstract}
Aim. To develop and psychometrically test the self-efficacy and performance in self-management support (SEPSS) instrument.

Background. Facilitating persons with a chronic condition to take an active role in the management of their condition, implicates that nurses acquire new competencies. An instrument that can validly and reliably measure nurses' performance and their perceived capacity to perform self-management support is needed to evaluate current practice and training in self-management support.

Design. Instrument development and psychometric testing of the content and construct validity, factor structure and reliability.

Methods. A literature review and expert consultation $(N=17)$ identified the content. The items were structured according to the Five-A's model and an overarching category of 'overall' competencies. The initial instrument was tested in a sample of 472 nurses and 51 nursing students from Belgium and the Netherlands, between June 2014-January 2015.

Results. Confirmatory factor analyses revealed satisfactory fit indices for the sixfactor structure. Discriminating power was demonstrated for subgroups. The overall internal consistency (Cronbach's alpha) was high both for the self-efficacy and the performance items. The test-retest intra-class correlation coefficients were good.

Conclusion. The SEPSS instrument is a 36 -item, Likert-scaled self-reporting instrument with good content and construct validity, and good internal consistency reliability and good test-retest reliability. Therefore, it is a promising instrument to measure self-efficacy and performance with regard to self-management support.
\end{abstract}

Keywords: competencies, instrument development, nursing, psychometric, reliability, self-management support, validity 
Ann Van Hecke PhD RN

Professor

University Centre for Nursing and

Midwifery, Department of Public Health,

Faculty of Medicine and Health Sciences,

Ghent University, Ghent, Belgium

Mathilde M.H. Strating PhD

Assistant Professor

Institute of Health Policy \& Management,

Erasmus University Rotterdam, Rotterdam, the Netherlands

\section{Introduction}

Chronic conditions account for more than half of the global disease burden (WHO 2014). The steadily increasing prevalence of people with chronic conditions poses new challenges for patients, healthcare providers and healthcare systems all over the world (Alwan et al. 2010, WHO 2014). The provision of self-management support (SMS) is internationally recognized as a core component of chronic care (Wagner et al. 2001, Nolte \& McKee 2008, WHO 2014). Self-management can be defined as: 'the individual's ability to manage symptoms, treatment, physical and psychosocial consequences and life style changes inherent in living with a chronic condition and to affect the cognitive, behavioural and emotional responses necessary to maintain a satisfactory quality of life. Thus, a dynamic and continuous process of self-regulation is established' (Barlow et al. 2002, p. 178). This definition would imply that patients are expected to take an active role in their treatment, for which they will need specific competencies. To support their patients' self-management, healthcare providers as well must assume a new role and acquire new competencies. In many countries, nurses are the ones who provide SMS (Alleyne et al. 2011). This new role, however, is not easily integrated in practice (Wilson et al. 2006, Hibbard et al. 2010, Elissen et al. 2013). Self-management support is based on a partnership between patients and nurses, which requires nurses to drop the nurse-expert role (Thorne et al. 2000, Hook 2006, McDonald et al. 2008) and expressions of control inpatient interactions (Lawn et al. 2013). Selfmanagement support demands a set of competencies on educational, supportive and communicational level in all phases of the support process (Nolte \& McKee 2008, Alleyne et al. 2011, Elissen et al. 2013). One of the leading models in organizing the process of SMS is the Five A's model describing five key activities (Assess, Advise, Agree,
Why is this instrument needed?

- To support their patients' self-management, nurses must assume a new role and acquire new competencies.

- A valid and reliable instrument is needed to measure the current practice, the educational needs and the effectiveness of training in self-management support.

- So far no attention has been given to the assessment of nurses' self-efficacy, which is a strong predictor of behaviour, in the context of self-management support.

\section{What are the key findings?}

- Competencies acquired for self-management support can be categorized according to the phases of the Five A's model, but also a sixth overarching category of competencies was identified, including, for example, partnership.

- The Self-Efficacy and Performance in Self-management Support instrument has good content and construct validity, and good internal consistency reliability.

How should the findings be used to influence practice and education?

- The Self-Efficacy and Performance in Self-management Support instrument is suitable to measure nurses' self-efficacy and performance with regard to self-management support.

- The self-reported results should serve as an outcome measure of self-management support practices in clinical and research settings, to identify educational needs and to evaluate personal growth.

Assist and Arrange) (Glasgow et al. 2003). This model provides a framework for professional behaviour in SMS and thereby facilitates the necessary steps in the provision of SMS. In the Assess phase, nurses must be capable of not only exploring patients' beliefs and motivation about living with the chronic condition but also of personalizing the support offered (Glasgow et al. 2006, Lawn et al. 2009). In the Advise phase, providing information about the disease and its symptoms is an important feature. Education is a precondition for informed decision-making - and consequently for self-management as well (Udlis 2011). The Agree phase requires skills for collaborative goal setting, during which process the nurse and patient together must agree on the goals to aim for, guided by previous positive experiences (Stacey et al. 2008, Schulman-Green et al. 2012). In the Assist phase, nurses need competencies to enable patients adapt their daily activities, which may include stimulating patients to seek professional help 
(Schulman-Green et al. 2012, Dwarswaard et al. 2015). The Arrange phase refers to organizing follow-up care. Selfmanagement support is a multidisciplinary approach which relies on effective information sharing and effective coordination of care (Pols 2009). Importantly, arrangements must be made to evaluate the progress in goal achievement (Glasgow et al. 2003). In addition, nurses need to possess overall competencies for a partnership attitude in each phase of the support process. This includes respecting patients' autonomy in shared decision-making, building a sustainable partnership and being able to reflect on one's own actions and recognize ethical dilemmas (Hostick \& McClelland 2002, Pols 2009, Sandman et al. 2012, Kayser et al. 2014).

Studies reveal a discrepancy between the expected proficiency of nurses and their actual performance on SMS (Elissen et al. 2013, Yank et al. 2013). One of the ways to improve the provision of SMS in chronic care is the training of healthcare providers (Zwar et al. 2006, Kosmala-Anderson et al. 2010a,b). Training is also likely to improve selfefficacy and thus performance of SMS as self-efficacy is a strong predictor of behaviour (Bandura 1991) and thereby an important precursor of SMS performance. To the best of our knowledge, there is no instrument to evaluate the confidence nurses have in their own SMS abilities.

A valid and reliable instrument assessing both performance and self-efficacy is useful to guide and measure the current practice, to identify educational needs and to assess the effectiveness of training programs.

\section{Background}

Several instruments are available to measure healthcare professionals' performance in SMS. These only address specific aspects, however. The Clinician Support-Patient Activation Measure (CS-PAM) measures beliefs about the importance of activating patients and of SMS (Hibbard et al. 2010). Decision support can be addressed with instruments such as the Observing Patient Involvement (OPTION) scale (Elwyn et al. 2013), the Shared Decision Making Questionnaire physician version (SDM-Q-Doc) (Scholl et al. 2012) and the Decision Support Analysis Tool (DSAT-10) (Stacey et al. 2008). Therapeutic alliance can be measured with the Kim Alliance Scale (KAS) (Kim et al. 2001); and skills in motivational interviewing with, for example, the Motivational Interviewing Treatment Integrity (MITI) (Moyers et al. 2005) or the Behavior Change Counselling Scale (BCCS) (Vallis 2013). To our knowledge, only the Practices in SMS (PSMS) covers the broad aspect of SMS (KosmalaAnderson et al. 2011). This 25-item instrument has three subscales: clinician SMS, organization of services to support self-management and patient centeredness, which all showed good internal consistency. However, nursing competencies to stimulate patients to take the lead in their selfmanagement are not addressed in detail.

These existing instruments typically focus on performance in SMS. It may be the case, however, that healthcare professionals have the required skills, but lack self-efficacy to effectively apply these skills (Bandura 1991, Kosmala-Anderson et al. 2010a,b). Self-efficacy refers to a person's confidence in the ability to perform a specific behaviour in a specific situation (Bandura 1991). Self-efficacy is known to affect behaviour by influencing the choices individuals make and the course of actions they pursue; it determines their level of effort, persistence and resilience (Bandura 2006).

The current evidence demonstrates that other factors than self-efficacy might affect a nurse's performance in SMS (Harris et al. 2008, Elissen et al. 2013), creating the potential risk of a discrepancy between self-efficacy and performance. Therefore, it is appropriate to develop an instrument that measures not only nurses' actual performance but also selfefficacy to perform SMS for people with chronic conditions.

\section{The study}

\section{Aim}

To develop and psychometrically test the Self-efficacy and Performance in Self-Management Support (SEPSS) instrument.

\section{Methodology}

A psychometric instrument validation study was conducted in two phases. Phase one included instrument development and the process of content validation by a panel of experts. Phase two entailed the psychometric evaluation in a sample of nurses and nursing students (Figure 1).

\section{Phase 1 Instrument development \& content validation}

First, a literature and concept search in scientific and grey literature was performed (March-November 2013) to identify relevant competencies for SMS. We searched in the PubMed, CINAHL and Cochrane databases for scientific articles about the concept of self-management and the required competencies for SMS, using the keywords 'selfcare', 'chronic disease', nurs* and competenc*. We also retrieved information from (inter)national policy documents on self-management. The processes of self-management in patients with chronic conditions, consisting of patient tasks and skills as described by Schulman-Green et al. (2012), formed the basis for a draft list. These processes were con- 
verted into competencies for SMS. Additionally, competencies such as partnership (Hostick \& McClelland 2000, Leisen \& Hyman 2001, Keatinge et al. 2002, Lorig \& Holman 2003, Visse et al. 2010), shared decision-making, collaborative goal setting (Lorig \& Holman 2003, Stacey et al. 2008, Kriston et al. 2010) and self-efficacy of the patient (Krichbaum et al. 2003, Lorig \& Holman 2003, Yank et al. 2013) were obtained from literature. The items in the list were structured according to the Five A's model described above (Glasgow et al. 2003). An overarching sixth category was added to cover 'overall' competencies for SMS that could not be related to one single step of the Five A's model (Leisen \& Hyman 2001, Hostick \& McClelland 2002, Glasgow et al. 2003, Pols 2009, Kriston et al. 2010, Visse et al. 2010). In the end, the draft list contained 37 competencies, grouped into six subscales: (1) Assess - assess the needs and beliefs of the patient, (2) Advise - give the patient information he needs, (3) Agree - set goals together with the patient, (4) Assist - assist the patient to overcome barriers, (5) Arrange - arrange follow-up care and (6) Overall competencies - a supportive attitude (Table 2).

This draft list was discussed by a convenience sample of experts in SMS $(N=10)$ during a 3-hour meeting. Given that the instrument should be appropriate for all healthcare settings and for educational purposes, the experts represented nurse education, hospital care, older people care and psychiatric care. During the meeting the relevance, appropriateness and exhaustiveness of the item pool were discussed. Following on from the qualitative comments of the experts, three competencies were excluded, three competencies were reformulated and six competencies were added. This resulted in a 40-item draft instrument. The grouping into the six subscales was approved by the experts. In the next step, the researchers split broad competencies into sub-competencies to allow detailed assessment, which increased the number of items to 53 .

The relevance and clarity of the 53-item instrument were pilot-tested in a new group of experts in SMS $(N=4)$, nurses $(N=8)$ and researchers $(N=5)$. This resulted in some minor adjustments that entailed mainly wording ambiguities and in a reduction by seven items due to overlap in content or meaning. To cover the content of each subscale and to allow for items to be deleted during the psychometric testing and refinement of the instrument, at least six items were included for each subscale. Phase one resulted in an initial 46-item instrument with established content validity, grouped into 6 subscales (Figure 1).

\section{Instrument}

The items were formulated to be measured on a five-point Likert rating scale. As the aim of the instrument was to assess both self-efficacy and performance in SMS, each item was assessed by two questions (additional File S1). Self-efficacy was measured by requesting participants to consider 'I think I can do this', with ratings from 'Not at all'(0), 'Not sufficient'(1), 'More or less'(2), 'Sufficient'(3), 'Good'(4). Actual performance was measured by requesting participants to consider 'I do this', with ratings from 'Never'(0), 'Rarely'(1), 'Occasionally'(2), 'Frequently'(3)-'Always'(4).

\section{Phase 2 Psychometric evaluation}

The psychometric evaluation (Figure 1) included the testing of the construct validity (confirmatory factor analysis, discriminating power) and reliability (internal consistency and stability) of the SEPSS instrument.

\section{Sample}

The 46-item instrument was tested in a sample of nurses and nursing students in Belgium and the Netherlands. The sample size aimed for was based on the recommended 10 respondents per item as a minimum to support the factor analysis for stable covariates (Polit \& Beck 2008). A total sample approach was used. In Belgium, 122 final-year nursing students were invited (response 51/122; 42\%) and 58 nurses combining their employment with attending an additional Master of Science in Nursing program (response $37 /$ 58; 64\%) participated. In the Netherlands, we invited 2054 nurses from an academic hospital and 107 nurses from a psychiatric institution. Respectively $345(17 \%)$ and 32 $(30 \%)$ participated in the validation study. Furthermore, 800 nurses employed in different healthcare settings and participating in a Dutch national panel of nurse professionals were invited (response 58/800; 7\%). This resulted in a total of 523 participants.

\section{Procedure}

Data were collected between June 2014 - January 2015. The nursing students completed a paper form of the selfreporting instrument. The nurses completed the questionnaire in an online format. Next to the items of the SEPSS, participants were asked for demographic variables and their perception of the importance of SMS, on a scale ranging from 1 ('not important at all')-10 ('very important'). To increase the response rate, for the online procedure, two reminders were sent and small rewards (e.g. movie tickets) were raffled among the participants. As the instrument can be used to measure current practice in SMS, its stability was evaluated using the test-retest procedure. For this purpose, a group of nursing students $(N=26)$ completed the instrument twice, with a 2-hour interval. This short interval was chosen to minimize the possible effect of confounding 


\section{PHASE 1: INSTRUMENT DEVELOPMENT \& CONTENT VALIDATION}

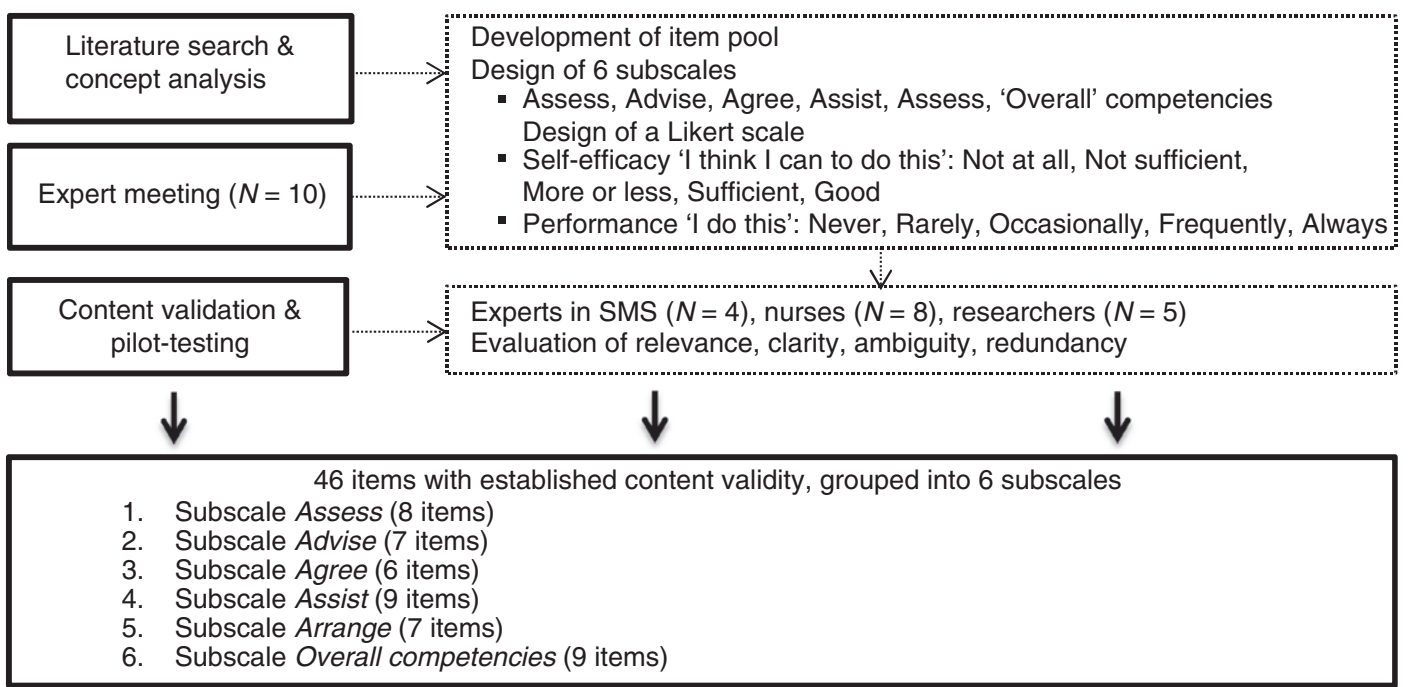

PHASE 2: PSYCHOMETRIC EVALUATION [nurses $(N=472)$, nursing students $(N=51)$ ]

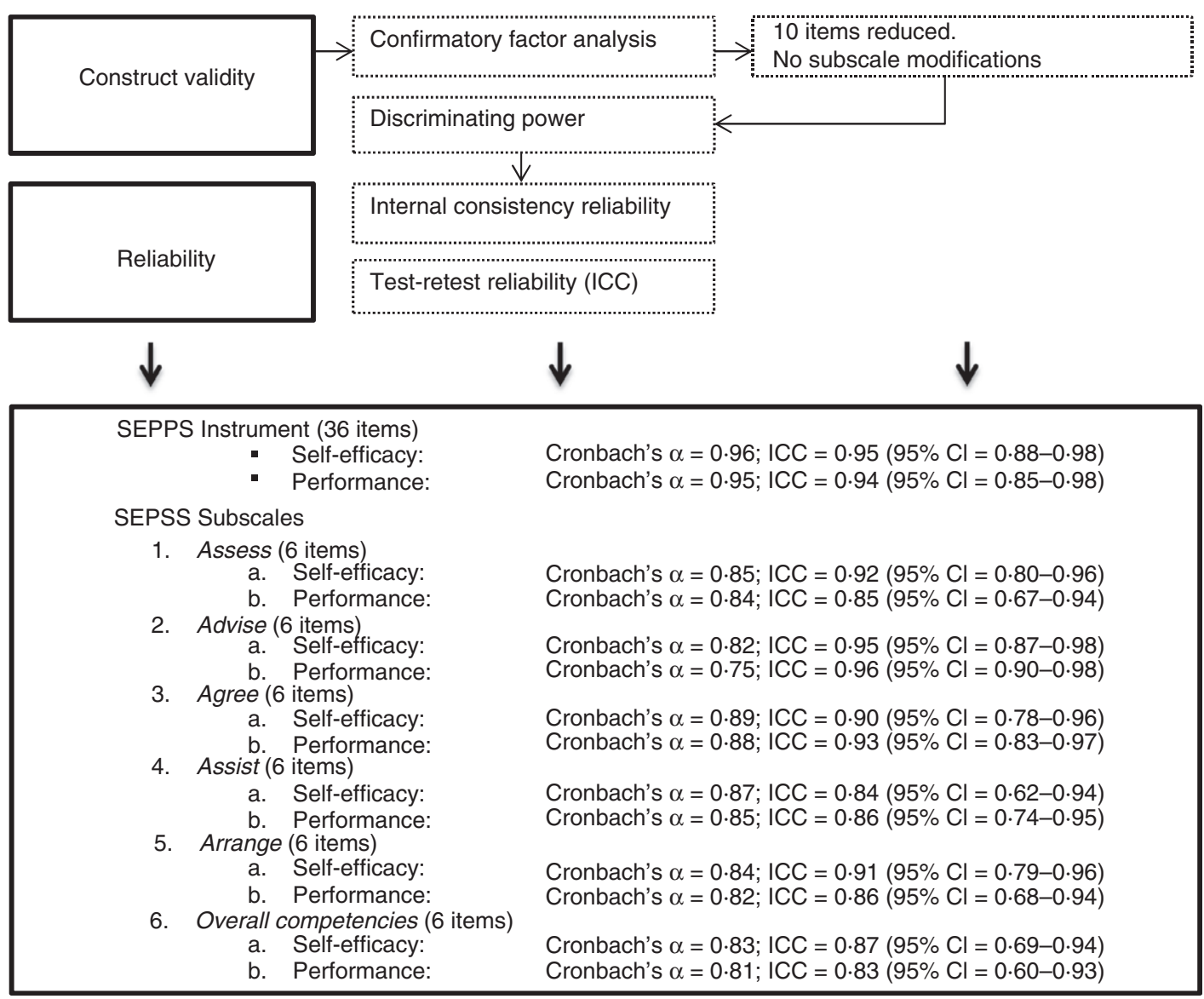

Figure 1 Developmental and validation process of the SEPSS - Instrument.

factors, such as learning by lectures or experiences on clinical placement and by spontaneous growth (Polit \& Beck 2008). The participants were not informed in advance about the test-retest procedure, making the procedure less sensitive to memory bias. The conditions were the same for both parts of the procedure. 


\section{Statistical analyses}

Statistical analyses were performed using SPSS21 (SPSS Inc., Chicago, IL, USA) and LISREL (version 8.8). A significance level of 0.05 was applied. Questionnaires with response patterns indicating a haphazard completion, that is, with a repetitive response pattern of at least 42 out of the 46 items, were excluded $(N=4)$. Mean scores were calculated at subscale level (range 0-4). The total score was calculated by summing the mean scores of the subscales for self-efficacy (range 0-24) and for performance (range 0-24) in SMS. Subscale scores were considered as missing when more than $10 \%$ of the items of that subscale were left open. These questionnaires were excluded from further calculations. The variables assessing self-efficacy and performance in SMS were normally distributed.

As the reliability testing of the total scale and subscales of the initial 46-item instrument yielded Cronbach's alphas between 0.79 and 0.97 , further validation was justified. Construct validity of the instrument was assessed by a confirmatory factor analysis and discriminating power (known-group technique). To verify the factor structure of the questionnaire and to test whether the relationship between observed variables and their underlying latent constructs exists, confirmatory factor analysis was executed using the LISREL program. No correlation errors either within or across sets of items were allowed in the model. Based on the Five A's model, each subset of items was allowed to load only on its corresponding latent construct. The 'overall' competence items only were allowed to load on a separate second order overarching latent construct. To improve the model fit and reduce the number of items in the instrument, items were removed from the original pool following three criteria: (1) items were excluded one by one following modification indices provided by LISREL and the strength of the loadings; (2) eliminating items was stopped when reliability of each subscale dropped below 0.80; and (3) there should be as few items as possible with a minimum of six, without loss of content and psychometric quality. Four indices of model fit were used. The cutoff criteria for these four indices were those proposed by $\mathrm{Hu}$ and Bentler (1999). First, the overall test of goodnessof-fit assesses the discrepancy between the model implied and the sample covariance matrix by means of a normaltheory weighted least squares test. A plausible model has low, preferably non-significant $\chi^{2}$ values. However, Chisquare is overly sensitive when the sample size is large (anything over 200), leading to difficulty in obtaining desired non-significant levels (Hayduk 1988). Second, the Root Means Square Error of Approximation (RMSEA) reflects the estimation error divided by the degrees of free- dom as a penalty function. Values on RMSEA below 0.06 indicate small differences between the estimated and observed model. Third, we used the Standardized Root Means square Residual (SRMR), which is a scale invariant index for global fit that ranges between 0 and 1 . Values on SRMR lower than 0.08 indicate a good fit. As a fourth index of model fit, the Incremental Fit Index (IFI) was calculated. This index compares the independence model (i.e. observed variables are unrelated) to the estimated model. Preferably, values on IFI should be larger than 0.95 . Exclusion of items was not solely based on modification indices. As the instrument heavily relies on literature and theoretical conceptualization, these considerations were taken into account when interpreting the statistical measures and were essential for decisions on exclusion of items.

Sample adequacy was tested by performing the KaiserMeyer-Olkin (KMO) measure over 0.50 and the Bartlett's test of sphericity. Further analyses were determined on the modified instrument (36 items). To study the discriminating power of the instrument, four subgroups with a theoretically expected difference in self-efficacy and performance in SMS were predefined: (1) nurses providing consultations in outpatients clinics vs. nurses working in inpatients units; (2) nurses vs. nursing students; (3) nurses with a master degree vs. those without a master degree; and (4) nurses perceiving SMS as highly important $(\geq 9)$ vs. nurses perceiving SMS of little or no importance $(\leq 6)$. Independent sample t-tests were used to calculate differences between the mean scores of these predefined groups guided by a Levene's test for equality of variances.

The reliability of the instrument was assessed by internal consistency analysis and by test-rest reliability (intraclass correlation). Inter-item correlations were calculated at subscale and at scale level, to determine the internal consistency of the instrument. A Cronbach's alpha higher than 0.80 was considered as satisfactory (Polit \& Beck 2008). The intraclass correlation (ICC) of the test-retest was calculated for each subscale and for the total score on self-efficacy and on performance by using a two-way random effects model with absolute agreement. Reliability coefficients of $\geq 0.70$ were considered as satisfactory (Polit \& Beck 2008).

Floor and ceiling effects refer to the proportions of individuals scoring near the bottom or the top respectively. A high floor or ceiling effect hampers to distinguish individuals from each other and to measure changes after intervention (Terwee et al. 2007). There is no consensus on the mathematical definition of floor and ceiling effects (Terwee et al. 2007). We determined a priori that floor or ceiling 
effects were present if $>15 \%$ of the nurses achieved values in the $12.5 \%$ lower and upper bound, respectively, of (sub) scale values.

\section{Translation}

For international publication and presentation purposes the initial 46-item instrument was translated from Dutch into English by an independent native speaker. Another independent professional translator re-translated the items in Dutch. The re-translated version was compared with the original wordings, to confirm the accuracy of the English translation. Discrepancies between the translations were resolved by consensus.

\section{Ethical considerations}

In Belgium, the study protocol was approved by the Ethical Review Committee of Ghent University Hospital (B670201422154 and B670201422381). While in the Netherlands no Research Ethics Committee approval was required, permission was obtained from the executive boards of all participating institutions. All participants received detailed information about the aim and procedures and were informed of confidentiality. The nursing students gave their written informed consent before completing the instrument. For the other participants, completing the online survey was considered as consent.

\section{Results}

\section{Sample characteristics}

The sample included 472 nurses and 51 nursing students. The nurses worked in different settings, more than half of them $(56 \%)$ on inpatient units in a general or academic hospital. About one sixth of the nurses $(16.6 \%)$ worked on an outpatient clinic providing consultations with chronically ill on a daily basis. For further details see Table 1.

\section{Construct validity}

Factor analysis

The confirmatory factor analysis on the self-efficacy items yielded the following results: $\chi^{2}$ was 12086; RMSEA 0.13; SRMR 0.11 and IFI 0.90 all indicating that the model was not yet sufficient. Factor loadings of this initial 46-item model ranged from $0 \cdot 44-0 \cdot 87$ (Table 2). Following the fac-
Table 1 Demographic characteristics of the sample.

\begin{tabular}{|c|c|c|}
\hline Characteristics $(N=523)$ & $N$ & $(\%)$ \\
\hline \multicolumn{3}{|l|}{ Gender } \\
\hline Female & 409 & $(78 \cdot 2)$ \\
\hline Male & 110 & $(21 \cdot 0)$ \\
\hline Missing & 4 & $(0 \cdot 8)$ \\
\hline \multicolumn{3}{|l|}{ Age (years) } \\
\hline$<23$ & 43 & $(8 \cdot 2)$ \\
\hline $23-29$ & 144 & $(27 \cdot 5)$ \\
\hline $30-39$ & 104 & $(19 \cdot 9)$ \\
\hline $40-49$ & 96 & $(18 \cdot 4)$ \\
\hline$>49$ & 132 & $(25 \cdot 2)$ \\
\hline Missing & 4 & $(0 \cdot 8)$ \\
\hline \multicolumn{3}{|l|}{ Setting } \\
\hline Student nurses & 51 & $(9 \cdot 7)$ \\
\hline \multicolumn{3}{|l|}{ Academic hospital } \\
\hline Inpatient units & 269 & $(51 \cdot 4)$ \\
\hline Outpatient clinics & 87 & $(16 \cdot 6)$ \\
\hline \multicolumn{3}{|l|}{ General hospital } \\
\hline Inpatient units & 24 & $(4 \cdot 6)$ \\
\hline Psychiatric institution & 33 & $(6 \cdot 4)$ \\
\hline Primary $\&$ elderly care nursing & 9 & $(1 \cdot 7)$ \\
\hline Other (not specified) & 50 & $(9 \cdot 6)$ \\
\hline \multicolumn{3}{|l|}{ Work experience (years) } \\
\hline $0-5$ & 124 & $(23 \cdot 7)$ \\
\hline $6-10$ & 97 & $(18 \cdot 5)$ \\
\hline $11-15$ & 58 & $(11 \cdot 1)$ \\
\hline$>15$ & 171 & $(32 \cdot 7)$ \\
\hline Missing & 73 & $(14 \cdot 0)$ \\
\hline \multicolumn{3}{|l|}{ Educational degree } \\
\hline Student nurses, vocational educational level & 51 & $(9.7)$ \\
\hline Vocational education level* & 100 & $(19 \cdot 1)$ \\
\hline Bachelor degree & 268 & $(51 \cdot 3)$ \\
\hline Master degree $^{\dagger}$ & 59 & $(11 \cdot 3)$ \\
\hline Missing & 45 & $(8 \cdot 6)$ \\
\hline
\end{tabular}

*Vocational educational level is a three years nurse training education at qualification level 5 of the European Higher Education Area.

${ }^{\dagger}$ Both academic and professional Master degrees.

tor loadings, modification indices and an internal consistency check of each subscale, the stepwise procedure, as described in the method section, resulted in the elimination of 10 items (bold in Table 2). The final model consisted of 36 items with six items for each subscale. This final model resulted in a better fit of the model, although the fit indices still showed room for improvement; $\chi^{2}$ decreased to 7238 ; RMSEA decreased to 0.12 ; SRMR decreased to 0.10 and IFI increased to $0 \cdot 93$. A similar procedure was done for the performance items, resulting in a similar fit of the model for both the initial and the final model. Also, the exact same items were removed following the procedure for improving the model. Sample adequacy was confirmed by the KMO test $(0.95)$ and Bartlett's test of sphericity 


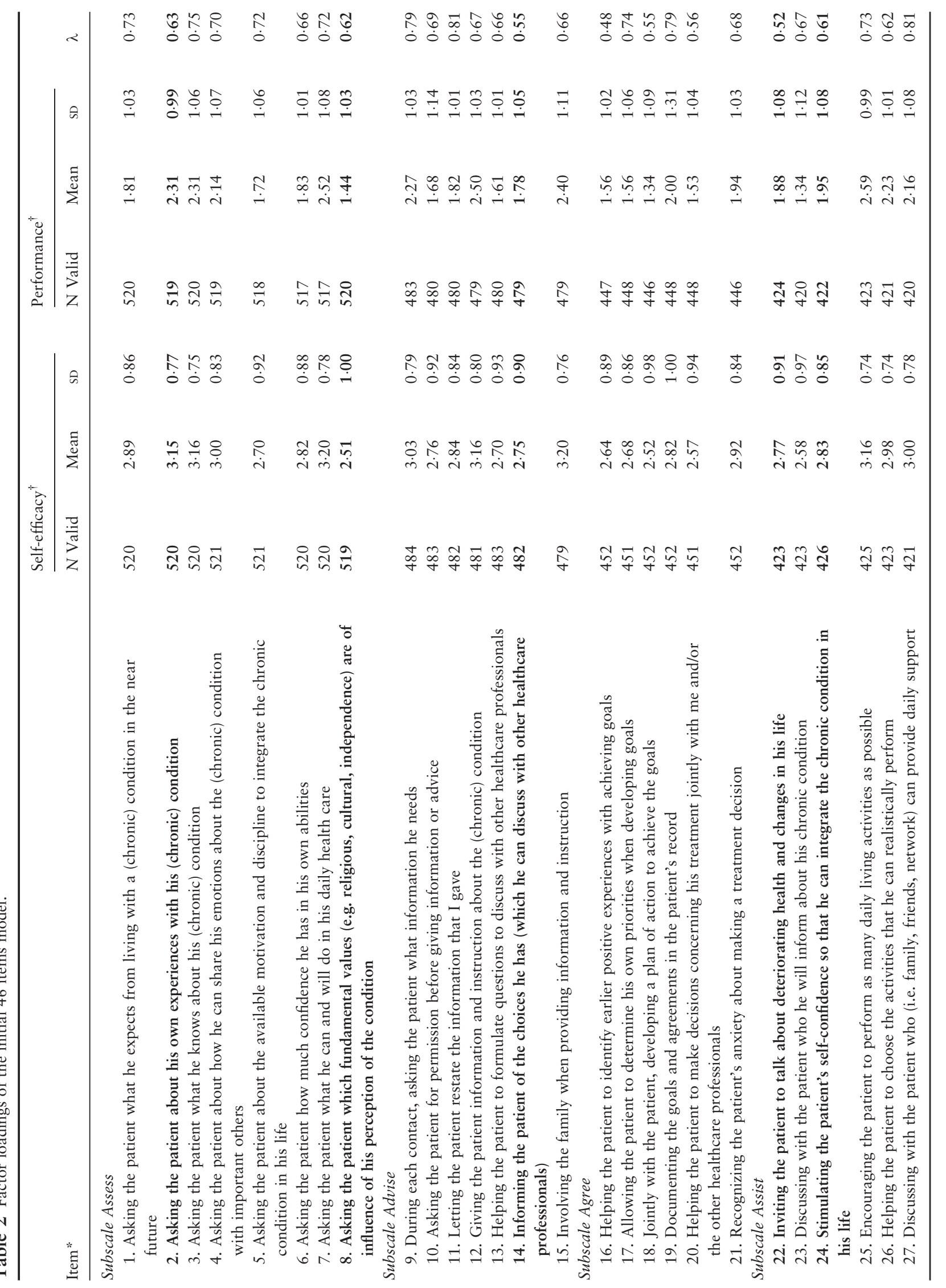




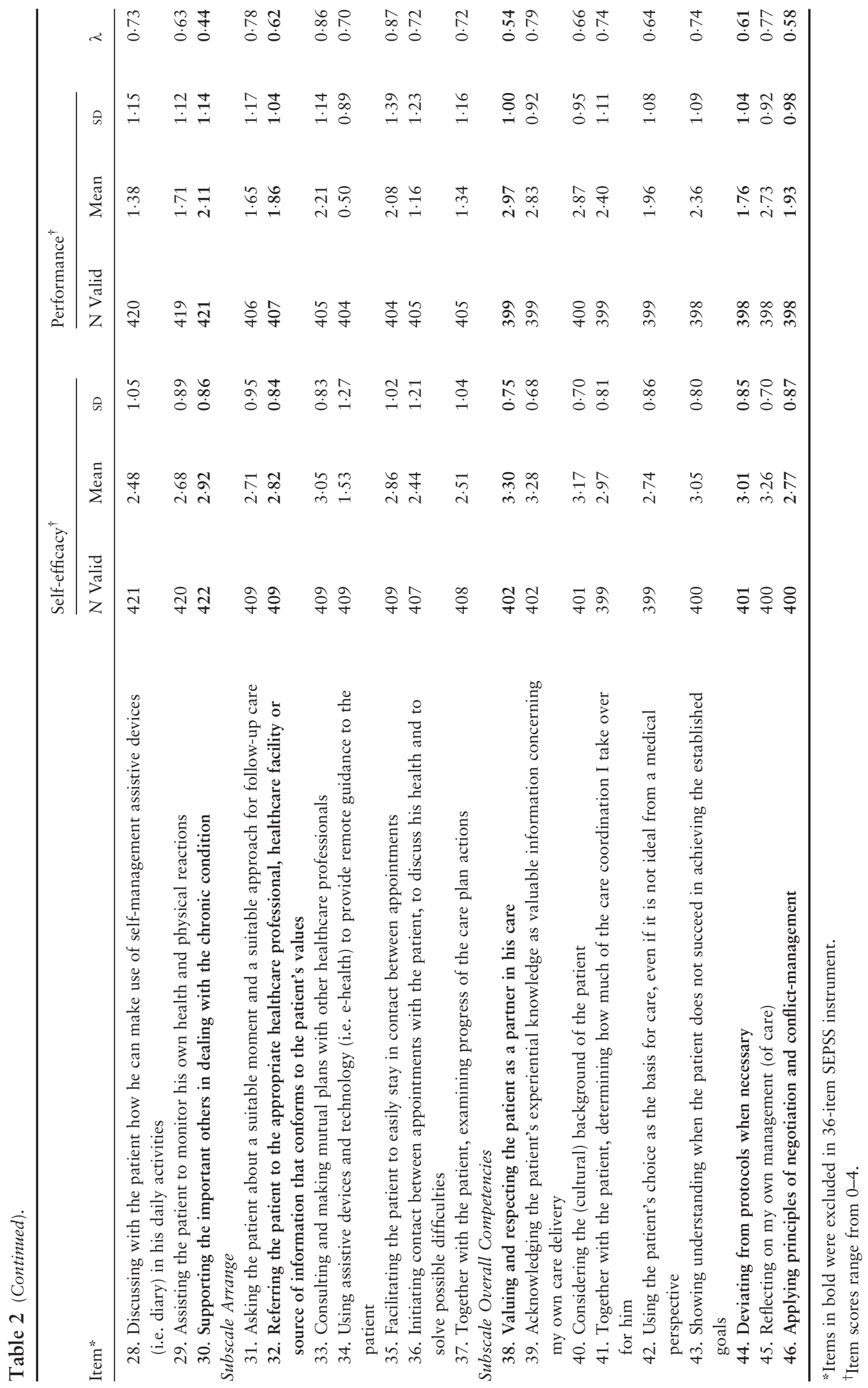


$\left(\chi^{2}=7654.23\right.$, d.f. $\left.=630, P<0.001\right)$ indicating that correlations between items did not occur by chance.

\section{Discriminating power}

The results on discriminating power demonstrated significant differences between most of the predefined groups, as shown in Table 3. Nurses providing outpatient consultations had higher scores than nurses in inpatients units at all subscales and at the total scale level for self-efficacy (respectively 18.71 vs. $16.75, t=3.70$, d.f. $=78.90, P<0.001$ ) and for performance (respectively 13.99 vs. $11.47, t=4.17$, d.f. $=78.58, P<0.001)$. Nurses had higher scores than nursing students at all subscales and at the total scale level for self-efficacy (total scores respectively 17.22 vs. 16.06, $t=2 \cdot 21$, d.f. $=394, P<0.05$ ) and for performance (respectively 12.02 vs. $9.39, t=4.23$, d.f. $=391, P<0.001)$. Nurses who perceived SMS as highly important had higher scores for self-efficacy than nurses believing SMS of little or no importance for chronic care, (total scores respectively 17.75 vs. $16.24, t=2.10$, d.f. $=108, P<0.05)$ and for performance (total scores respectively 12.60 vs. 11.33, $t=1.73$, d.f. $=108, \quad P<0.05)$. Nurses with a master degree had higher levels of performance than those without such a degree (total scores respectively 13.00 vs. 11.54 , $t=2 \cdot 38$, d.f. $=74.16, P<0.05)$, but self-efficacy did not significantly differ between these groups (17.48 vs. 17.07, $t=0.94$, d.f. $=366, P=0.35$ ).

\section{Reliability}

Internal consistency

Cronbach's alpha was 0.96 for the total self-efficacy scale. For the subscales of self-efficacy and performance, Cronbach's alpha values are displayed in Figure 1.

\section{Test-retest stability}

A group of 26 final-year nursing students completed the questionnaire twice. On the first occasion the mean total score for self-efficacy was 16.84 (SD 3.65) and for performance in SMS 10.45 (SD 4.28). At retest, the corresponding figures were 15.51 (SD 5.51) and 9.78 (SD 4.97). The overall intra-class correlation coefficient was $0.95(95 \% \mathrm{CI}=0.88$ $0.98)$ for the self-efficacy items and $0.94(95 \% \mathrm{CI}=0.85$ 0.98 ) for the performance items. The intra-class correlation coefficients for the subscales are displayed in Figure 1.

\section{Floor and ceiling effects}

Table 4 presents the proportions of nurses scoring in the $12.5 \%$ lower and upper bound, respectively, of (sub)scale values. Floor or ceiling effects were not found, apart from a ceiling effect for the Overall Competence scale concerning self-efficacy.

\section{Discussion}

As self-management has become the leading paradigm for chronic care in many countries, it is essential to develop SMS training programs for nurses and to measure the effectiveness of these programs. In this regard, the SEPSS instrument provides for accurate assessment of a nurse's performance and self-efficacy in applying SMS. Other than the PSMS instrument (Kosmala-Anderson et al. 2011), the SEPSS places an emphasis on competencies needed to stimulate patients to take the lead in self-managing their chronic condition.

The SEPSS instrument assesses the performance and the self-efficacy of essential competencies for SMS derived from literature and expert advice, complemented with competencies reflecting key attitudes, such as partnership and patient centred-care. It relies on a broad holistic perspective on SMS, based on what patients need to take the lead in selfmanaging their chronic condition (Schulman-Green et al. 2012). Although the instrument uses the framework of the Five A's model, familiarity with this model is not a prerequisite for using the SEPSS. The underlying competencies are feasible for all professionals supporting self-management.

Regarding construct validity of the SEPSS, the confirmatory factor analysis yielded satisfactory fit with the 36-item SEPSS instrument, wherein the 'overall' competencies can be considered as overarching for the other five subscales according to the Five A's model. By removing 10 items, we aimed to develop a brief instrument that still has enough sensitivity to measure what it is supposed to measure. For that reason, we did not allow $\alpha<0.80$ and maintained at least six items in each subscale. Although the fit indices showed room for improvement, factor loadings were high and sample adequacy to perform the factor analysis was confirmed by the KMO test and Bartlett's test of sphericity. The results of the known-group technique analysis supported the discriminating properties of the instrument, with expected higher levels of self-efficacy and performance in SMS. Discriminating properties at self-efficacy level were not provided for masters educated nurses; yet they demonstrated a markedly higher performance than non-mastereducated nurses. Master-educated nurses are supposed to possess the reflective and critical thinking abilities needed in more complex care settings (ter Maten-Speksnijder et al. 2012). A more reflective attitude on professional performance is desirable, but can make persons more stringent in judging their self-efficacy (Desmedt 2004, Koole et al. 
Table 3 Discriminating power of the SEPSS instrument (known groups).

\begin{tabular}{|c|c|c|c|c|c|c|}
\hline \multirow[b]{2}{*}{ Group } & \multirow[b]{2}{*}{$N$} & \multicolumn{2}{|c|}{ Mean (max. 30) $(S D)$} & \multirow[b]{2}{*}{$t$} & \multirow[b]{2}{*}{ d.f. } & \multirow[b]{2}{*}{$P$ values } \\
\hline & & $\begin{array}{l}\text { Group with } \\
\text { theoretically } \\
\text { expected higher } \\
\text { score (A) }\end{array}$ & $\begin{array}{l}\text { Group with } \\
\text { theoretically } \\
\text { expected } \\
\text { lower score (B) }\end{array}$ & & & \\
\hline \multicolumn{7}{|l|}{ Self-efficacy items } \\
\hline Nurses providing consultations (A) & 60 & $18 \cdot 71(3 \cdot 81)$ & $16.75(2.92)$ & $3 \cdot 70$ & $78 \cdot 90$ & $<0 \cdot 001$ \\
\hline vs. Nurses on hospital units (B) & 219 & & & & & \\
\hline Nurses (A) & 352 & $17 \cdot 22(3 \cdot 22)$ & $16 \cdot 06(3 \cdot 83)$ & $2 \cdot 21$ & 394 & 0.03 \\
\hline vs. Nursing students (B) & 44 & & & & & \\
\hline Nurses with a master degree $(\mathrm{A})$ & 59 & $17.48(3.68)$ & $17 \cdot 07(3 \cdot 26)$ & $0 \cdot 94$ & 366 & $0 \cdot 35$ \\
\hline vs. nurses without master degree (B) & 309 & & & & & \\
\hline Nurses perceiving SMS highly important* (A) & 87 & $17.75(3.05)$ & $16 \cdot 24(3 \cdot 09)$ & $2 \cdot 10$ & 108 & $0 \cdot 04$ \\
\hline vs. nurses perceiving SMS of little to no importance ${ }^{\dagger}(\mathrm{B})$ & 23 & & & & & \\
\hline \multicolumn{7}{|l|}{ Performance items } \\
\hline Nurses providing consultations (A) & 60 & $13.99(4 \cdot 36)$ & $11.47(3 \cdot 31)$ & $4 \cdot 17$ & $78 \cdot 58$ & $<0 \cdot 001$ \\
\hline vs. Nurses on hospital units (B) & 219 & & & & & \\
\hline Nurses (A) & 352 & $12 \cdot 02(3 \cdot 74)$ & $9.39(3.97)$ & $4 \cdot 23$ & 391 & $<0 \cdot 001$ \\
\hline vs. Nursing students (B) & 41 & & & & & \\
\hline Nurses with a master degree (A) & 59 & $13.00(4.43)$ & $11 \cdot 54(3 \cdot 70)$ & $2 \cdot 38$ & $74 \cdot 16$ & 0.02 \\
\hline vs. nurses without master degree (B) & 306 & & & & & \\
\hline Nurses perceiving SMS highly important* (A) & 87 & $12 \cdot 60(3 \cdot 26)$ & $11.33(2.67)$ & $1 \cdot 73$ & 108 & $0 \cdot 02$ \\
\hline vs. nurses perceiving SMS of little to no importance ${ }^{\dagger}(\mathrm{B})$ & 23 & & & & & \\
\hline
\end{tabular}

*Score $\geq 9$.

${ }^{\dagger}$ Score $\leq 6$.

$t$, value independent sample $t$-test; d.f., degrees of freedom.

Table 4 Subscale and scale scores, including floor and ceiling effects (\%).

\begin{tabular}{|c|c|c|c|c|c|c|c|c|}
\hline & \multicolumn{4}{|c|}{ Self-efficacy } & \multicolumn{4}{|c|}{ Performance } \\
\hline & Mean & SD & $\begin{array}{l}\% \\
\text { Min }\end{array}$ & $\begin{array}{l}\% \\
\operatorname{Max}\end{array}$ & Mean & SD & $\begin{array}{l}\% \\
\text { Min }\end{array}$ & $\begin{array}{l}\% \\
\operatorname{Max}\end{array}$ \\
\hline Subscale Assess* & $2 \cdot 96$ & 0.63 & 0.40 & $11 \cdot 90$ & $2 \cdot 05$ & 0.78 & 1.60 & $2 \cdot 50$ \\
\hline Subscale Advise & $2 \cdot 94$ & 0.61 & $0 \cdot 20$ & $12 \cdot 70$ & $2 \cdot 05$ & 0.71 & $1 \cdot 00$ & $1 \cdot 50$ \\
\hline Subscale Agree & $2 \cdot 69$ & 0.74 & $1 \cdot 10$ & $6 \cdot 20$ & 1.66 & $0 \cdot 86$ & $7 \cdot 20$ & $1 \cdot 30$ \\
\hline Subscale Assist & $2 \cdot 81$ & 0.67 & 0.00 & $11 \cdot 20$ & 1.90 & $0 \cdot 82$ & $2 \cdot 60$ & $2 \cdot 10$ \\
\hline Subscale Arrange & $2 \cdot 51$ & 0.79 & $0 \cdot 20$ & $7 \cdot 60$ & 1.49 & $0 \cdot 85$ & $10 \cdot 90$ & 1.00 \\
\hline Subscale Overall Competencies & 3.08 & 0.56 & 0.00 & $16 \cdot 00$ & 2.53 & 0.73 & 0.00 & $4 \cdot 50$ \\
\hline Total scale ${ }^{\dagger}$ & 17.09 & $3 \cdot 31$ & 0.00 & $11 \cdot 10$ & 11.75 & $3 \cdot 84$ & 0.00 & 1.00 \\
\hline
\end{tabular}

*Subscale scores range from $0-4$.

${ }^{\dagger}$ Scale scores range from $0-24$.

2012). This might explain why masters educated nurses performed better, while being more prudent in the confidence of their own capacities. The small proportion of master-educated nurses, whereby equal variance between groups could not be assumed at performance level, may also explain these unexpected results. Nevertheless, some between-group differences could be the result of insufficient variation in professional status (nurses vs. students) between the country samples and thereby reflect differences in conceptualization and implementation about SMS between both countries, rather than predefined group differences.

The evidence to support the internal consistency of the instrument and its sub-scales was strong. The high Cronbach's alpha values, ranging from 0.75-0.96, indicate a good to very good internal consistency or homogeneity for the instrument and for the subscales. The results of the test-retest procedure indicate that the stability of the instrument was good, as the intra-class correlations reached the recommended values $\geq 0 \cdot 70$. Hardly any floor 
or ceiling effects were found, indicating the possibility to distinguish between individuals and to measure changes after intervention. Attention is needed on the estimation of self-efficacy for the Overall Competencies, reflecting the self-efficacy towards having a partnership attitude, as an effect might be missed due to a possible ceiling effect.

The SEPSS is an instrument that captures nurses' performance and self-efficacy in performing SMS. Given the importance of self-efficacy as a precursor for behaviour (Bandura 1991), we strongly recommend to assess the performance and self-efficacy items in an integrated way, so as to make it feasible to work simultaneously on both areas where needed. The division in the six subscales enables to measure outcomes on subscale level and to focus on a particular aspect of the SMS-process, while the total score presents a more overall view of how SMS is provided. Scores range from $0-4$ for the subscales and from $0-24$ at total scale level. Higher scores on the SEPSS instrument reflect a higher level of self-efficacy or performance in SMS.

As the format of the SEPSS instrument requires nurses' to rate both self-efficacy and performance on the same set of items, a high correlation between both was not unimaginable in view of the possibility of maintaining some coherence and consistency in responses. However, the response patterns for self-efficacy and performance differed markedly, as evidenced by the moderate correlation $(r=0.63$, $P<0.001$ ) found.

The instrument has several potential applications for healthcare settings shifting towards SMS. First, the assessment of current SMS practice from a self-reported perspective, which may bring to light competencies that require training at an individual or department level. Second, this assessment can help trainers in tailoring the content and teaching strategies of training courses. Third, but this is a more reflective application, making nurses aware of possible discrepancies between their confidence and their performance and the causes of these discrepancies. Fourth, training effectiveness and personal growth through training can be evaluated, and the effectiveness of other interventions aimed at improving SMS competencies. However, the instrument's sensitivity to change has not yet been established. Fifth, the total scale score could be useful to monitor fidelity of SMS implementation.

Considering that SMS is the responsibility of a multidisciplinary team whose members are expected to possess the same competencies (Wagner et al. 2001), it is recommended to investigate the psychometric characteristics in groups of other healthcare professionals than the nurses and nursing students in this study. To ensure international validity we encourage initiatives to translate the SEPSS instrument into other languages and to validate it for use in the respective countries.

\section{Limitations}

The study had some limitations. First, the low response rate in some subsamples and the lack of knowledge on the reasons for drop-out during the online completion of the questionnaire, might limit the generalizability of the findings. Nevertheless, we were able to recruit a heterogeneous sample from different settings, representing nurses with and without experience in SMS and from two different countries, each having a different history about self-management. This heterogeneity may have enhanced the representativeness of the sample. Second, the test-retest procedure was performed in a small group and the intensive procedure may have adversely affected attention during completion of the retest. Besides, the short time interval could have inflated the ICC values by the recall of the statements, although this seems not so obvious for a comprehensive tool. Therefore, the results of the stability tests should be considered an initial trend. Further stability testing in a larger sample is recommended. Third, by measuring at one point in time, we were not yet able to establish the instruments' sensitivity to change in competence development, which is one of the proposed applications. In the future, we intend to use the SEPSS to measure the effect of SMS training.

\section{Conclusion}

In view of its good psychometric properties, the new SEPSS instrument is a promising instrument to measure nurses' self-efficacy and performance with regard to SMS. The selfreported results could serve as an outcome measure of SMS practices in clinical and research settings, to identify educational needs and to evaluate personal growth and to assess the effectiveness of training or other interventions to improve SMS.

\section{Acknowledgements}

We express our thanks to Claudia Gamel and Ko Hagoort for the English translation of the SEPPS. We thank the experts who were consulted in the development process of the instrument. We also thank the Belgium and Dutch nurses and nursing students who participated in this study by completing the questionnaire. We are grateful to Ko for linguistical and editorial support. 


\section{Funding}

Ghent University: No external funding; Rotterdam University of Applied Sciences: this study forms part of the Research Program NURSE-CC: Rotterdam Consortium for NUrsing Research into Self-management and Empowerment in Chronic Care, funded by the Netherlands Organization for Health Research and Development (Grant number 520001004).

\section{Conflict of interest}

The authors declare that they have no competing interests.

\section{Author contributions}

Study design: VD, SvH, MS, JD, AvS, AVH. Data collection \& -analysis: VD, SvH, MS. Manuscript preparation: VD, SvH, MS, JD, AvS, AVH.

All authors have agreed on the final version and meet at least one of the following criteria [recommended by the ICMJE (http://www.icmje.org/recommendations/)]:

- substantial contributions to conception and design, acquisition of data or analysis and interpretation of data;

- drafting the article or revising it critically for important intellectual content.

\section{Supporting Information}

Additional Supporting Information may be found in the online version of this article at the publisher's web-site.

\section{References}

Alleyne G., Hancock C. \& Hughes P. (2011) Chronic and noncommunicable diseases: a critical challenge for nurses globally. International Nursing Review 58(3), 328-331. doi:10.1111/ j.1466-7657.2011.00912.x.

Alwan A., Maclean D.R., Riley L.M., d'Espaignet E.T., Mathers C.D., Stevens G.A. \& Bettcher D. (2010) Monitoring and surveillance of chronic non-communicable diseases: progress and capacity in high-burden countries. Lancet, 376(9755), 18611868. doi: 10.1016/S0140-6736(10)61853-3.

Bandura A. (1991) Social cognitive theory of self-regulation. Organizational Behavior and Human Decision Processes 50(2), 248-287. doi:10.1016/0749-5978(91)90022-L.

Bandura A. (2006) Guide for Constructing Self-Efficacy Scales. SelfEfficacy Beliefs of Adolescents, vol. 5. Pajares F. \& Urdan T., eds, Information Age Publishing, Greenwich CT, pp. 307-337.

Barlow J., Wright C., Sheasby J., Turner A. \& Hainsworth J. (2002) Self-management approaches for people with chronic conditions: a review. Patient Education and Counseling 48(2), 177-187. doi:10.1016/S0738-3991(02)00032-0.
Desmedt E. (2004) Research Into the Theoretical Base of Learning Styles in View of Educational Applications in a University Setting. Ghent University, Ghent.

Dwarswaard J., Bakker E.J., van Staa A. \& Boeije H.R. (2015) Self-management support from the perspective of patients with a chronic condition: a thematic synthesis of qualitative studies. Health Expectations. doi:10.1111/hex.12346.

Elissen A., Nolte E., Knai C., Brunn M., Chevreul K., Conklin A. \& Vrijhoef H. (2013) Is Europe putting theory into practice? A qualitative study of the level of self-management support in chronic care management approaches. BMC Health Services Research 13(1), 117. doi:10.1186/1472-6963-13-117.

Elwyn G., Tsulukidze M., Edwards A., Légaré F. \& Newcombe R. (2013) Using a 'talk' model of shared decision making to propose an observation-based measure: Observer OPTION5 Item. Patient Education and Counseling 93(2), 265-271. doi:10.1016/j.pec.2013.08.005.

Glasgow R.E., Davis C.L., Funnell M.M. \& Beck A. (2003) Implementing practical interventions to support chronic illness self-management. Joint Commission Journal on Quality Safety 29(11), 563-574.

Glasgow R.E., Emont S. \& Miller D.C. (2006) Assessing delivery of the five 'As' for patient-centered counseling. Health Promotion International 21(3), 245-255. doi:10.1093/heapro/dal017.

Harris M.F., Williams A.M., Dennis S.M., Zwar N.A. \& Davies G.P. (2008) Chronic disease self-management: implementation with and within Australian general practice. Medical Journal of Australia 189(10), S17-S20.

Hayduk L.A. (1988) Structural Equation Modeling With LISREL: Essentials and Advances. Johns Hopkins University Press, Baltimore \& London.

Hibbard J.H., Collins P.A., Mahoney E. \& Baker L.H. (2010) The development and testing of a measure assessing clinician beliefs about patient self-management. Health Expectations 13(1), 6572. doi:10.1111/j.1369-7625.2009.00571.x.

Hook M.L. (2006) Partnering with patients - a concept ready for action. Journal of Advanced Nursing 56(2), 133-143.

Hostick T. \& McClelland F. (2000) 'Partnership': a co-operative inquiry between community mental health nurses and their clients. 1. Research methodology, process and reflections. Journal of Psychiatric and Mental Health Nursing 7(4), 307-313. doi:10.1046/j.1365-2850.2000.00304.x.

Hostick T. \& McClelland F. (2002) 'Partnership': a co-operative inquiry between Community Mental Health Nurses and their clients. 2. The nurse-client relationship. Journal of Psychiatric and Mental Health Nursing 9(1), 111-117. doi:10.1046/j.13510126.2001.00457.x.

Hu L.T. \& Bentler P.M. (1999) Cutoff criteria for fit indexes in covariance structure analysis: Conventional criteria versus new alternatives. Structural Equation Modeling: A Multidisciplinary Journal 6(1), 1-55.

Kayser J.W., Cossette S. \& Alderson M. (2014) Autonomysupportive intervention: an evolutionary concept analysis. Journal of Advanced Nursing 70(6), 1254-1266. doi:10.1111/jan12292.

Keatinge D., Bellchambers H., Bujack E., Cholowski K., Conway J. \& Neal P. (2002) Communication: Principal barrier to nurseconsumer partnerships. International Journal of Nursing Practice 8(1), 16-22. doi:10.1046/j.1440-172x.2002.00344.x. 
Kim S.C., Boren D. \& Solem S.L. (2001) The Kim Alliance Scale: development and preliminary testing. Clinical Nursing Research 10(3), 314.

Koole S., Dornan T., Aper L., Scherpbier A., Valcke M., CohenSchotanus J. \& Derese A. (2012) Does reflection have an effect upon case-solving abilities of undergraduate medical students? BMC Medical Education 12(1), 75.

Kosmala-Anderson J., Wallace L.M. \& Turner A. (2010a) Does the professional and working context of United Kingdom clinicians predict if they use practices to support patients with long term conditions to self manage. Archives of Medical Science 6, 815821.

Kosmala-Anderson J.P., Wallace L.M. \& Turner A. (2010b) Confidence matters: a Self-Determination Theory study of factors determining engagement in self-management support practices of UK clinicians. Psychology Health \& Medicine 15(4), 478-491. doi:10.1080/13548506.2010.487104.

Kosmala-Anderson J., Wallace L.M., Turner A. \& Barwell F. (2011) Development and psychometric properties of a self report measure to assess clinicians' practices in self management support for patients with long term conditions. Patient Education and Counseling 85(3), 475-480. doi:10.1016/ j.pec.2010.10.007.

Krichbaum K., Aarestad V. \& Buethe M. (2003) Exploring the connection between self-efficacy and effective diabetes selfmanagement. The Diabetes Educator 29(4), 653-662.

Kriston L., Scholl I., Hölzel L., Simon D., Loh A. \& Härter M. (2010) The 9-item Shared Decision Making Questionnaire (SDM-Q-9). Development and psychometric properties in a primary care sample. Patient Education and Counseling 80(1), 94-99. doi:10.1016/j.pec.2009.09.034.

Lawn S., Battersby M., Lindner H., Mathews R., Morris S., Wells L. \& Reed R. (2009) What skills do primary health care professionals need to provide effective self-management support? Seeking consumer perspectives. Australian Journal of Primary Health 15(1), 37-44. doi:10.1071/PY08053.

Lawn S., Delany T., Sweet L., Battersby M. \& Skinner T.C. (2013) Control in chronic condition self-care management: how it occurs in the health worker-client relationship and implications for client empowerment. Journal of Advanced Nursing 70(2), 383-394. doi:10.1111/jan.12203.

Leisen B. \& Hyman M.R. (2001) An improved scale for assessing patients' trust in their physician. Health Marketing Quarterly 19 (1), 23-42. doi:10.1300/J026v19n01_03.

Lorig K.R. \& Holman H. (2003) Self-management education: history, definition, outcomes and mechanisms. Annals of Behavioral Medicine 26(1), 1-7. doi:10.1207/S15324796 ABM2601_01.

ter Maten-Speksnijder A.J., Grypdonck M.H., Pool A. \& Streumer J.N. (2012) Learning opportunities in case studies for becoming a reflective nurse practitioner. Journal of Nursing Education 51 (10), 563-569. doi:10.3928/01484834-20120820-05.

McDonald R., Rogers A. \& Macdonald W. (2008) Dependence and identity: nurses and chronic conditions in a primary care setting. Journal of Health Organization and Management 22(3), 294-308. doi:10.1108/14777260810883558.

Moyers T.B., Martin T., Manuel J.K., Hendrickson S.M. \& Miller W.R. (2005) Assessing competence in the use of motivational interviewing. Journal of Substance Abuse Treatment 28(1), 1926.

Nolte E. \& McKee M. (2008) Caring For People With Chronic Conditions: A Health System Perspective: A Health System Perspective. McGraw-Hill International, Berkshire.

Polit D.F. \& Beck C.T. (2008) Nursing Research: Generating and Assessing Evidence for Nursing Practice. Lippincott Williams \& Wilkins, Philadelphia.

Pols R.G. (2009) Chronic condition self-management support: proposed competencies for medical students. Chronic Illness 5 (1), 7-14. doi:10.1177/1742395308098888.

Sandman L., Granger B.B., Ekman I. \& Munthe C. (2012) Adherence, shared decision-making and patient autonomy. Medicine, Health Care and Philosophy 15(2), 115-127. doi:10.1007/s11019-011-9336-x.

Scholl I., Kriston L., Dirmaier J., Buchholz A. \& Härter M. (2012) Development and psychometric properties of the Shared Decision Making Questionnaire-physician version (SDM-Q-Doc). Patient Education and Counseling 88(2), 284-290. doi:10.1016/ j.pec.2012.03.005.

Schulman-Green D., Jaser S., Martin F., Alonzo A., Grey M., McCorkle R. \& Whittemore R. (2012) Processes of selfmanagement in chronic illness. Journal of Nursing Scholarship 44(2), 136-144. doi:10.1111/j.1547-5069.2012. 01444.x.

Stacey D., Taljaard M., Drake E.R. \& O’Connor A.M. (2008) Audit and feedback using the brief Decision Support Analysis Tool (DSAT-10) to evaluate nurse-standardized patient encounters. Patient Education and Counseling 73(3), 519-525. doi:10.1016/j.pec.2008.07.016.

Terwee C.B., Bot S.D., de Boer M.R., van der Windt D.A., Knol D.L., Dekker J. \& de Vet H.C. (2007) Quality criteria were proposed for measurement properties of health status questionnaires. Journal of Clinical Epidemiology 60(1), 34-42.

Thorne S.E., Ternulf Nyhlin K. \& Paterson B.L. (2000) Attitudes toward patient expertise in chronic illness. International Journal of Nursing Studies 37(4), 303-311. doi:10.1016/S0020-7489(00) 00007-9.

Udlis K.A. (2011) Self-management in chronic illness: concept and dimensional analysis. Journal of Nursing and Healthcare of Chronic Illness 3(2), 130-139. doi:10.1111/j.1752-9824.2011. 01085.x.

Vallis M. (2013) Behaviour change counselling - how do i know if $\mathrm{i}$ am doing it well? The development of the Behaviour Change Counselling Scale (BCCS). Canadian Journal of Diabetes 37(1), $18-26$.

Visse M.A., Teunissen T., Peters A., Widdershoven G.A.M. \& Abma T.A. (2010) Dialogue for air, air for dialogue: towards shared responsibilities in COPD practice. Health Care Analysis 18(4), 358-373. doi:10.1007/s10728-009-0139-7.

Wagner E.H., Austin B.T., Davis C., Hindmarsh M., Schaefer J. \& Bonomi A. (2001) Improving chronic illness care: Translating evidence into action. Health Affairs 20(6), 64-78. doi:10.1377/ hlthaff.20.6.64.

WHO (2014) Global Status Report on Noncommunicable Diseases. Attaining the Nine Global Noncommunicable Diseases Targets; a Shared Responsibility. World Health Organization, Geneva. 
Wilson P.M., Kendall S. \& Brooks F. (2006) Nurses' responses to expert patients: the rhetoric and reality of self-management in long-term conditions: a grounded theory study. International Journal of Nursing Studies 43(7), 803-818. doi:10.1016/ j.ijnurstu.2005.10.011.

Yank V., Laurent D., Plant K. \& Lorig K. (2013) Web-based selfmanagement support training for health professionals: a pilot study. Patient Education and Counseling 90(1), 29-37. doi:10.1016/j.pec.2012.09.003.

Zwar N., Harris M., Griffiths R., Roland M., Dennis S., Powell Davies G. \& Hasan I. (2006) A Systematic Review of Chronic Disease Management. Research Centre for Primary Health Care and Equity, School of Public Health and Community Medicine, UNSW, New South Wales.

The Journal of Advanced Nursing (JAN) is an international, peer-reviewed, scientific journal. JAN contributes to the advancement of evidence-based nursing, midwifery and health care by disseminating high quality research and scholarship of contemporary relevance and with potential to advance knowledge for practice, education, management or policy. JAN publishes research reviews, original research reports and methodological and theoretical papers.

For further information, please visit JAN on the Wiley Online Library website: www.wileyonlinelibrary.com/journal/jan

$\underline{\text { Reasons to publish your work in } J A N \text { : }}$

- High-impact forum: the world's most cited nursing journal, with an Impact Factor of 1.527 - ranked 14/101 in the 2012 ISI Journal Citation Reports (C) (Nursing (Social Science)).

- Most read nursing journal in the world: over 3 million articles downloaded online per year and accessible in over 10,000 libraries worldwide (including over 3,500 in developing countries with free or low cost access).

- Fast and easy online submission: online submission at http://mc.manuscriptcentral.com/jan.

- Positive publishing experience: rapid double-blind peer review with constructive feedback.

- Rapid online publication in five weeks: average time from final manuscript arriving in production to online publication.

- Online Open: the option to pay to make your article freely and openly accessible to non-subscribers upon publication on Wiley Online Library, as well as the option to deposit the article in your own or your funding agency's preferred archive (e.g. PubMed). 